\title{
Treatment Targets in Inflammatory Bowel Disease: Current Status in Daily Practice
}

\author{
Tessa E.H. Römkens ${ }^{1,2}$, Kim Gijsbers ${ }^{1}$, Wietske Kievit ${ }^{3}$, Frank Hoentjen ${ }^{1}$, Joost P.H. Drenth ${ }^{1}$
}

\author{
1) Department of \\ Gastroenterology and \\ Hepatology, Radboud \\ University Nijmegen Medical \\ Centre, Nijmegen; \\ 2) Department of \\ Gastroenterology and \\ Hepatology, Jeroen Bosch \\ Hospital, 's Hertogenbosch; \\ 3) Radboud university medical \\ center, Radboud Institute for \\ Health Sciences, Nijmegen, \\ The Netherlands
}

\begin{abstract}
Background \& Aims: Recently, treatment goals in inflammatory bowel disease (IBD) in clinical trials have shifted from mainly symptom-based to more mucosa-driven. Real world data on treatment priorities are lacking. We aimed to investigate the current practice and most commonly used definitions of IBD treatment targets among Dutch gastroenterologists.

Methods: Dutch gastroenterologists were asked to participate in a computer-based nation-wide survey. We asked questions on demographics, opinion and current practice regarding IBD treatment targets.

Results: Twenty-four percent (134/556) of the respondents completed the survey. For both Crohn's disease (CD) $(47.3 \%, 61 / 129)$ and ulcerative colitis (UC) $(45 \%, 58 / 129)$ the main treatment goal was to achieve and maintain deep remission, defined as clinical, biochemical and endoscopic remission. Seventy-six percent of the participants use mucosal healing $(\mathrm{MH})$ as a potential treatment target for IBD, whereas $22.6 \%$ use histological remission. There is no single definition for $\mathrm{MH}$ in IBD. The majority use Mayo score $\leq 1$ in UC (52\%) and 'macroscopic normal mucosa' in CD (66\%).

Conclusion: More stringent and mucosa-driven treatment targets as 'deep remission' and 'mucosal healing' have found traction in clinical practice. The most commonly used definition for $\mathrm{MH}$ in routine practice is endoscopic MAYO score $\leq 1$ in UC and 'macroscopic normal mucosa' in CD.
\end{abstract}

Key words: Inflammatory bowel disease - mucosal healing - treatment goals - deep remission - ulcerative colitis - Crohn's disease.

Abbreviations: CD: Crohn's disease; CDEIS: Crohn's Disease Endoscopic Index of Severity; IBD: Inflammatory Bowel Disease; IBDU: IBD unclassified; IOIBD: International Organization for the Study of Inflammatory Bowel Diseases; MH: Mucosal healing; MMH: Microscopic mucosal healing; PROMS: Patient reported outcome measures; SES-CD: Simple endoscopic score for Crohn's disease; UC: ulcerative colitis; UCEIS: Ulcerative Colitis Endoscopic Index of Severity.

\section{INTRODUCTION}

Treatment targets in Inflammatory Bowel Disease (IBD) have shifted over the recent years. Therapeutic strategies focusing on induction and maintenance of clinical remission have no effect on the natural course of the disease [ 1 , 2]. In the late 1990s, the advent of biologic agents for the treatment of IBD has taught us that while patients may be in clinical remission, they may still have ongoing mucosal inflammation resulting in structural damage [3-8]. This has led to the concept of mucosal healing $(\mathrm{MH})$ as a more meaningful therapeutic target in clinical practice. Indeed, emerging data suggest that $\mathrm{MH}$ is strongly associated with a reduction in steroid use, complications, hospitalizations, and surgeries. This has fueled a shift in IBD trials and guidelines from mainly symptom-based management of IBD patients to more complex management considerations. Composite treatment targets including both patient reported outcome measures (PROMS) and mucosal healing are promoted $[9-15,34]$. Despite the clinical relevance of $\mathrm{MH}$, no standardized definition is available yet. In addition, definitions for newly defined, but not yet widely accepted targets, such as "deep remission" or "histological remission" are emerging in clinical trials. There are a number of endoscopic disease activity scores that assist endoscopists, but few have been properly evaluated and validated in large cohorts. 
Good examples are the Ulcerative Colitis Endoscopic Index of Severity (UCEIS) for ulcerative colitis (UC) [16, 17], the Crohn's Disease Endoscopic Index of Severity (CDEIS) and the Simple Endoscopic Score (SES-CD) for Crohn's disease (CD) [18-20]. Practical and commonly used definitions for $\mathrm{MH}$ such as "the complete resolution of the visible alteration or lesions" [21], or endoscopic Mayo score $\leq 1$ [22] have the disadvantage of higher interobserver variability and limited accuracy $[9$, $23,24]$. In view of the above, (inter)national guidelines are still unclear which treatment goals we should use in routine clinical practice, and how much efforts, risks and resources we should use to achieve implementation [25-28]. This leads to the question how endoscopic endpoints such as $\mathrm{MH}$ are used in real world IBD practices.

Therefore, we conducted a survey to investigate the current practice and used definitions of IBD treatment targets among Dutch gastroenterologists. In addition, we aimed to map factors that influence decision-making in clinical practice.

\section{METHODS}

\section{Survey development, testing and distribution}

We developed a structured survey on IBD management in daily practice consisting of 23 multiple-choice questions (Q1-23) including 3 clinical cases and 3 endoscopy images (Supplementary Appendix). The cases and images were mainly designed to monitor the internal consistency of the survey. Academic review of important literature and guidelines on this topic, as well as gastroenterologist's interviews guided the survey development. The survey was published at the professional survey website www.surveymonkey.com between June 2015 and October 2015. In accordance with survey design guidelines [29], a pilot questionnaire was pre-tested on 5 dedicated IBD gastroenterologists to examine for questionnaire applicability, clarity, and content validity. As a result of this pilot survey, the initial questionnaire was modified. The questionnaire was shortened, questions asked on treatment targets were made more clear and specific, 'other' response options were included, and the clinical cases were refined. The questionnaire (Supplementary Appendix) led to collection of data on demographics of participants and their institutes (7 questions), their opinion and current clinical practice with respect to IBD treatment targets (13 questions, of which 3 contained endoscopy images) and the most relevant decisionmaking factors in their clinical IBD practice (3 cases). With respect to IBD treatment targets, we asked both general and more detailed questions. To ensure that participants should only answer for those relevant survey questions, we redirected those that answered negatively on general questions in a specific topic to the next cluster of questions on the subsequent topic.

\section{Participants}

The survey and two reminders were distributed to potential participants through e-mail. A cover e-mail explained the purpose of the survey and provided a link to the survey. Responses were accepted up to 4 months from the initial survey distribution date. Participants comprised all Dutch gastroenterologists and gastroenterology (GI) fellows, who were members of the Dutch association for gastroenterologists.
As the survey was based on voluntary participation and information disclosure, the study protocol did not need to undergo a formal review by an Ethics Committee. Voluntary survey return was taken as consent.

\section{Data collection and statistics}

Data collection was anonymous and treated confidentially. Statistical analyses were performed using descriptive statistics, independent t-tests, and nonparametric tests. We used descriptive statistics to analyze the results using counts and proportions for categorical data and means and standard deviations for continuous variables. Missing values were not imputed. The answers to most questions regarding definition, treatment goals and the case descriptions were tested against the mean number of years of experience ( $\mathrm{t}$-test after dichotomization) and type of hospital (chi-square). We assumed a two-tailed $\mathrm{p}<0.05$ as statistically significant. We examined the consistency of the participants' answers by testing associations between theoretical questions and clinical cases or endoscopy images concerning the same subject (chi-square). Interobserver agreement for endoscopy images was tested by kappa statistics. Statistical analysis was performed with IBM SPSS version 22, excel version 2007, and GraphPad Prism (GraphPad Software,version 5.03).

\section{RESULTS}

\section{Participants}

The survey was sent to 556 eligible e-mail addresses. Overall, 134 physicians participated and completed the survey (24\%). The response rate was $25 \%$ for gastroenterologists $(n=97 / 396)$ and $23 \%$ for GI fellows $(n=37 / 160)$. Table I contains the demographic characteristics of the participants and their working environment. Fifty-nine percent of the participants were male (79/134), mean age was 42.1 years and the mean duration of working experience as a gastroenterologist was 8.5 years (fellows reported 0 on this question).

Table I. Demographic characteristics of the participants

\begin{tabular}{lc}
\hline Variable & $\mathrm{n} / \mathrm{N}(\%)$ \\
\hline Response rate GI fellows & $37 / 160(23 \%)$ \\
Response rate gastroenterologists & $97 / 396(25 \%)$ \\
Male sex & $79 / 134(59 \%)$ \\
Age (years) (mean \pm SD) & $42.1 \pm 9.8($ range $28-65)$ \\
Type of hospital & \\
University hospital & $44 / 134(33 \%)$ \\
Teaching hospital & $59 / 134(44 \%)$ \\
General hospital & $31 / 134(23 \%)$ \\
IBD population\# & \\
$<400$ & $10 / 134(8 \%)$ \\
$400-800$ & $44 / 134(33 \%)$ \\
$800-1200$ & $38 / 134(28 \%)$ \\
$>1200$ & $42 / 134(31 \%)$ \\
Treat IBD in practice & $130 / 134(97 \%)$ \\
\hline
\end{tabular}

IBD = inflammatory bowel disease; \# total number of IBD patients in follow up at the outpatient clinic of the center 


\section{Survey topics}

\section{Treatment goals (Q8-9)}

All selectable treatment goals, and their range are depicted in Fig. 1. The main overall treatment goal was to achieve and maintain deep remission for both CD $(47.3 \%, 61 / 129)$ and UC $(45 \%, 58 / 129)$. In this survey, this was defined as clinical, biochemical and endoscopic remission. Participants who indicated deep remission as a key treatment goal $(\mathrm{N}=61$ in $\mathrm{CD}, \mathrm{N}=58$ in UC), had fewer years of working experience. This was significant for CD $(11.5 \pm 9.8$ vs $6.0 \pm 7.3$ years ; $\mathrm{p}=$ 0.001 ); for UC the same trend was seen, but this did not reach the threshold for statistical significance $(10.2 \pm 9.5$ versus $7.2 \pm$ 8.5 years; $\mathrm{p}=0.06$ ). We found no association between treatment goals and the type of hospital (Table II).

\section{Mucosal healing and definitions (Q10-13)}

Seventy-six percent (98/129) of the participants indicated that they used $\mathrm{MH}$ as a potential treatment target for IBD. Years of working experience or type of hospital were independent of the use of $\mathrm{MH}$ (Table II). Ninety-four participants (73\%) answered more detailed questions on $\mathrm{MH}$. The majority (70\%; 66/94) mentioned that they used $\mathrm{MH}$ as endpoints for both CD, IBD unclassified (IBDU) and UC.

To define $\mathrm{MH}$ in UC, 52\% (49/94) used the Mayo score, with $40 \%$ (38/94) using 'macroscopic normal mucosa' as a definition for MH (Fig. 2a). For UC, we did not detect an association with the type of definition used for $\mathrm{MH}$ and years of working experience (Table II). The majority of respondents $(66 \% ; 62 / 94)$ used 'macroscopic normal mucosa' to define $\mathrm{MH}$ in CD, with almost one-fifth $(18.1 \% ; 17 / 94)$ using the CDEIS, and $9.6 \%(9 / 94)$ the SES-CD (Fig. 2b). Again, we found no association with the type of definition used for $\mathrm{MH}$ and years of working experience, but in university hospitals the $\mathrm{MH}$ definition 'macroscopic normal mucosa' was used significantly more often $(\mathrm{p}=0.043)$ (Table II).

\section{Histological remission (microscopic mucosal healing) and} deep remission $(\mathrm{Q} 14-\mathrm{Q} 17)$

Histological remission (microscopic mucosal healing, $\mathrm{MMH})$ as a possible treatment target for IBD was used by $22.6 \%(28 / 124)$ of the participants. Twenty-seven participants (22\%) provided additional details on MMH. Fifty-nine percent (16/27) stated to use MMH for CD, as well as for IBDU and UC, with $22.2 \%(6 / 27)$ using it only in UC. The most frequently used definition of $\mathrm{MMH}$ was 'perfectly normal mucosa' (44.4\%; 12/27). This was followed by the criteria of Truelove and Richards (29.6\%; 8/27) (Fig. 2c). There was no association between the used definition of MMH and years of working experience or type of hospital (Table II).

The participants defined deep remission frequently as 'clinical, biochemical and endoscopic remission' (56.5\%; 70/124), with the definition 'clinical, biochemical, endoscopic and histological remission' (39.5\%; 49/124) following suit (Fig. $2 \mathrm{~d}$ ). There was no association between the latter (most stringent definition of deep remission) and years of working experience or type of hospital (Table II).

\section{Endoscopy images (Q18-20)}

One hundred and twenty-four participants (93\%) assessed 3 endoscopy images of the colonic mucosa on $\mathrm{MH}$, to monitor for internal consistency of the survey. The 3 images linked to circle diagrams indicating the opinion of the participants on $\mathrm{MH}$ are depicted in Supplementary Fig. 3a-c. The inter
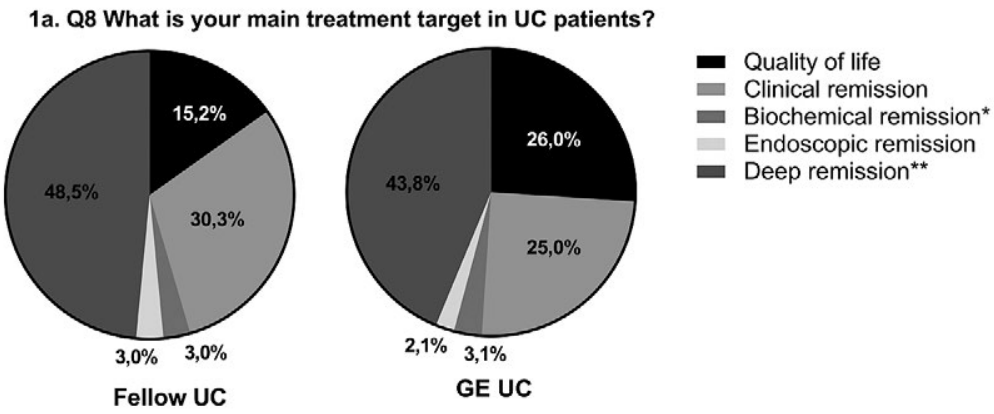

1b. Q9 What is your main treatment target in CD patients?

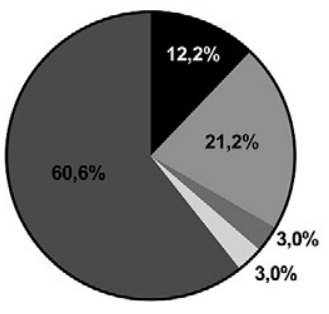

Fellow CD

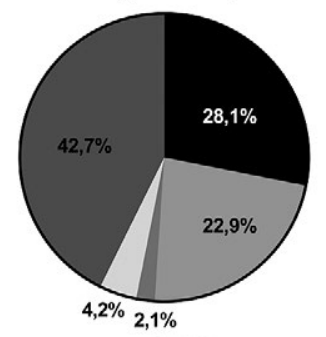

GE CD

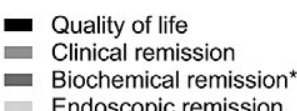

- Biochemical remission

- Deep remission**

Fig. 1. Selectable treatment targets in ulcerative colitis (1a) and Crohn's disease (1b) $\left({ }^{*}\right.$ Defined as normal laboratory results and normal fecal calprotectine; ${ }^{*}$ Defined as clinical, biochemical and endoscopic remission; $\mathrm{MH}=$ mucosal healing; $\mathrm{UC}=$ ulcerative colitis; $\mathrm{CD}=$ Crohn's disease; $\mathrm{GE}=$ gastroenterologist). 
Table II. Survey answers tested against working experience and type of hospital

\begin{tabular}{|c|c|c|c|c|c|c|c|}
\hline \multirow[t]{2}{*}{ Question (Q) } & \multirow[t]{2}{*}{$\mathrm{N}$} & \multirow{2}{*}{$\begin{array}{l}\text { Working } \\
\text { Experience }\end{array}$} & \multirow[t]{2}{*}{$\mathrm{P}$} & \multicolumn{3}{|c|}{ Type of hospital } & \multirow[t]{2}{*}{$\mathrm{P}$} \\
\hline & & & & University & Teaching & General & \\
\hline Q8 Treatment goal UC deep remission & 58 & $10.3 \pm 9.5$ & 0.06 & $21(36 \%)$ & $20(48 \%)$ & $17(61 \%)$ & \multirow[b]{2}{*}{0.08} \\
\hline Q8 Treatment goal UC other answers & 71 & $7.22 \pm 8.5$ & & $38(64 \%)$ & $22(52 \%)$ & $11(39 \%)$ & \\
\hline Q9 Treatment goal CD deep remission & 61 & $6.0 \pm 7.3$ & \multirow[t]{2}{*}{0.001} & $25(42 \%)$ & $21(50 \%)$ & $15(54 \%)$ & \multirow[b]{2}{*}{0.57} \\
\hline Q9 Treatment goal CD other answers & 68 & $11.5 \pm 9.8$ & & $34(58 \%)$ & $21(50 \%)$ & $13(46 \%)$ & \\
\hline Q10 MH used as treatment goal - yes & 98 & $8.6 \pm 9.0$ & \multirow[t]{2}{*}{0.57} & $49(83 \%)$ & $31(74 \%)$ & $18(64 \%)$ & \multirow[b]{2}{*}{0.15} \\
\hline Q10 MH used as treatment goal - no & 31 & $9.7 \pm 9.6$ & & $10(17 \%)$ & $11(26 \%)$ & $10(36 \%)$ & \\
\hline Q12 Definition MH in UC- macr.normal & 38 & $10.6 \pm 9.7$ & \multirow[t]{3}{*}{0.31} & $24(50 \%)$ & $9(30 \%)$ & $5(31 \%)$ & \multirow{3}{*}{0.08} \\
\hline Q12 Definition MH in UC- Mayo & 50 & $7.8 \pm 8.8$ & & $22(46 \%)$ & $20(67 \%)$ & $8(50 \%)$ & \\
\hline Q12 Definition $\mathrm{MH}$ in UC- other & 6 & $7.0 \pm 5.8$ & & $2(4 \%)$ & $1(3 \%)$ & $3(19 \%)$ & \\
\hline Q13 Definition $\mathrm{MH}$ in CD- macr.normal & 63 & $9.5 \pm 8.9$ & \multirow[t]{2}{*}{0.34} & $37(77 \%)$ & $19(63 \%)$ & $7(44 \%)$ & \multirow[b]{2}{*}{$0.04^{\mathrm{b}}$} \\
\hline Q13 Definition $\mathrm{MH}$ in CD- other & 31 & $7.6 \pm 9.4$ & & $11(23 \%)$ & $11(37 \%)$ & $9(56 \%)$ & \\
\hline Q14 Stringent definition deep remission & 49 & $9.0 \pm 8.9$ & \multirow[t]{2}{*}{0.92} & $24(42 \%)$ & $16(39 \%)$ & $9(35 \%)$ & \multirow[b]{2}{*}{0.81} \\
\hline Q14 Other definition deep remission- & 75 & $9.2 \pm 9.4$ & & $33(58 \%)$ & $25(61 \%)$ & $17(65 \%)$ & \\
\hline Q15 MMH used as treatment goal -yes- & 28 & $11.5 \pm 8.1$ & \multirow[t]{2}{*}{0.12} & $14(25 \%)$ & $9(22 \%)$ & $5(19 \%)$ & \multirow[b]{2}{*}{0.86} \\
\hline Q15 MMH used as treatment goal -no- & 96 & $8.5 \pm 9.4$ & & $43(75 \%)$ & $32(78 \%)$ & $21(81 \%)$ & \\
\hline
\end{tabular}

ayears; mean \pm SD; ${ }^{b} \mathrm{P} 0.013$ University hospital versus General; $\mathrm{MH}=$ mucosal healing; UC= ulcerative colitis; CD = Crohn's disease; $\mathrm{MMH}=$ histological remission.

observer agreement depicted as Fleiss generalized kappa was almost perfect for respectively image $\mathrm{A}(0.94)$ and image $\mathrm{B}$ (0.88) and moderate for image $\mathrm{C}(0.53)$. To control for internal consistency, we compared answers of Q12 ('which definition do you use for mucosal healing?') with the judgment of the endoscopic image $C$. For this purpose we created two groups: 1) $\mathrm{MH}$ defined as Mayo score 0 (answer Q12b); 2) MH defined as Mayo score $\leq 1$ (answer Q12c). Some 68\% (43/63) of the participants in group 1 judged image $\mathrm{C}$ as $\mathrm{MH}$, while $48 \%$ $(10 / 21)$ did from group $2(\mathrm{p}=0.09)$.

\section{Clinical cases (Q21-23)}

The survey comprised three clinical cases (Q21-23). The first 2 cases (Q21-22) dealt with the use of deep remission in UC patients (Supplementary Fig. 4a-b), and were used to test internal consistency of the survey. Question $8(\mathrm{Q} 8)$ is 2a. Q12 Definition Mucosal Healing in Ulcerative Colitis?

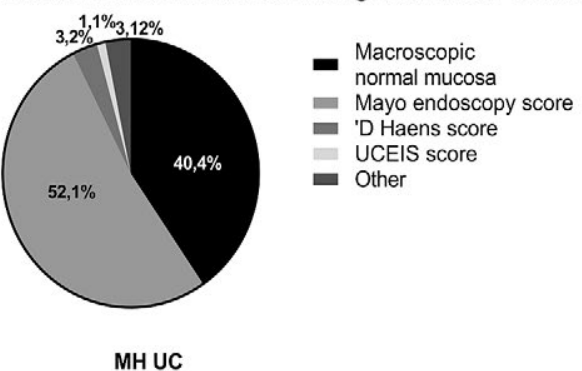

2c. Q17 Definition Microscopic Mucosal Healing

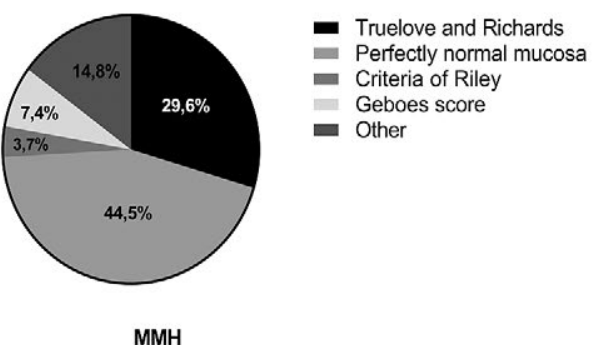

2b. Q13 Definition Mucosal Healing in Crohn's Disease

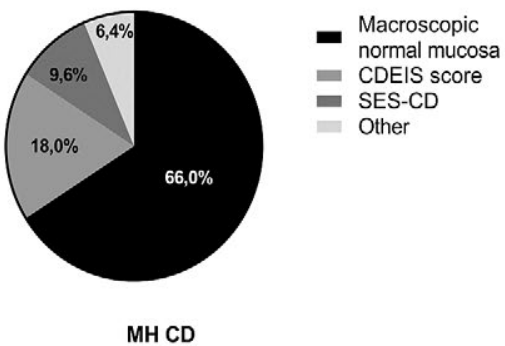

2d. Q14 Definition Deep Remission

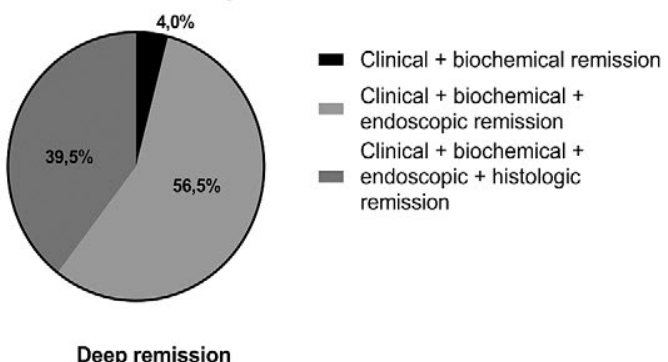

Fig. 2. Definitions used for mucosal healing in ulcerative colitis (2a), in Crohn's disease (2b), for histological remission (2c) and for deep remission in inflammatory bowel disease $(2 \mathrm{~d}) .(\mathrm{MH}=$ mucosal healing; $\mathrm{UC}=$ ulcerative colitis; $\mathrm{CD}=$ Crohn's disease; $\mathrm{MMH}=$ histological remission) 
the theoretical part that complements these 2 cases ("what do you consider the most important treatment target in your patients with UC') and therefore we analyzed the internal consistency of the participants by comparing the answers of Q8 and Q21/22 ( $\mathrm{n}=120)$. For both cases and Q8, we created two groups of respondents: 1) treatment target is deep remission (answer Q8e) versus 2) all other answers (answer Q8a-d). Most respondents chose to intensify their treatment in both cases (Q21: 75\%; 92/124 /Q22: 84\%; 103/123 ), with a significant association with the answer 'deep remission' in Q8 for both $\mathrm{Q} 21(\mathrm{p}=0.026)$ and Q22 ( $\mathrm{p}=0.03)$. The third case $(\mathrm{Q} 23)$ dealt with 'stopping criteria' for IBD medication after one year of deep remission in UC, an issue that is outside the scope of this article. Fifty-three percent (65/122) of the participants were willing to stop the immunosuppressive medication in a young male patient, who was in deep remission for 1.5 years, but was initially treated top-down because of severe pancolitis at presentation.

\section{DISCUSSION}

This nationwide survey was designed to determine the current practice of IBD treatment targets among Dutch gastroenterologists and to assess factors that influence decision making. Almost half of all respondents use deep remission as a key treatment goal. Deep remission was mostly defined as 'clinical, biochemical and endoscopic remission'. The majority are willing to intensify treatment to reach deep remission. Over three-quarters of the gastroenterologists use $\mathrm{MH}$ as a potential treatment target for IBD, whereas less than a quarter use histological remission. There is no single definition for $\mathrm{MH}$ in IBD. The majority use Mayo score $\leq 1$ in UC and 'macroscopic normal mucosa' in CD.

Nowadays, $\mathrm{MH}$ is an accepted treatment target in clinical IBD trials $[9,15,21]$ and has been accepted in the guidelines [25-28]. We found that $75 \%$ of the gastroenterologists use $\mathrm{MH}$ in daily IBD practice, irrespective of experience or type of hospital. Our data suggest that the concept of $\mathrm{MH}$ is embraced by many IBD practices. This indicates a watershed with the situation in 2010 when a Swiss survey found that gastroenterologists judged clinical activity as more relevant than endoscopic severity or biomarkers [30]. Worth noting, and probably partly explaining the discrepancy, is that the Swiss participants were all gastroenterologists, with on average, a longer working experience, with probably less IBD patients in their center. However, it remains important to realise that we cannot achieve MH in all IBD patients with the currently available therapies. In UC, varying data on achieving $\mathrm{MH}$ with the use of 5-ASA $(36,9 \%-80 \%)[31,32]$, azathioprine (53\%) [33] and biologics 32\%-62\% [34-37] exist, depending on the used definition of $\mathrm{MH}$ and duration of follow up. In the case of CD similar results for budesonide (24\%)[38], azathioprine (16.5-73\%)[38-40], combinations of azathioprine and biologics $(43,9-70.4 \%)[39,40]$, and biologics (20\%-63\%) [39-42] exist.

Newly defined treatment targets, such as deep or histological remission come from endpoints defined for clinical IBD trials [40,43-44], but are not widely accepted or integrated in the IBD guidelines [25-28]. Surprisingly, almost half of all respondents used deep remission as a key treatment target in daily clinical practice, which suggests that practice is being shaped prior to development or revision of guidelines. Most guidelines date from around 2011 and are updated every 3 years [25-27]. Indeed, a recent consensus meeting initiated by the International Organization for the Study of Inflammatory Bowel Diseases (IOIBD) did define composite treatment targets for both UC and CD, combining both clinical and endoscopic remission [45]. Also, the majority of these respondents have fewer years of working experience. Possibly, a greater focus on evolving treatment targets in the current training schemes of GI fellows plays a role here. Histological remission appears to be used less often in daily practice, with a preference for UC when used. This is in line with international guidelines that do not advise histological remission as a treatment target [25-27]. Also, IOIBD experts agreed upon histological remission as an adjunctive goal that might come into view in the future, in particular in UC [45]. A unified single definition for MH in IBD is lacking. For UC, several endoscopic scoring systems have been developed but none were validated until recently [46-47]. In 2012, the UCEIS has been developed and validated [16, 17]. UCEIS is rather complex and time consuming, which makes it less attractive for routine use in daily practice [48]. Currently, the IOIBD consensus group recommends the endoscopic Mayo score in UC because of its ease of use and established predictive value $[45,49-50]$. In line with this recommendation we found that more than half of the participants use the Mayo score $(0$ or $\leq 1$ ) to define $\mathrm{MH}$ in UC. Of these, one-third defined $\mathrm{MH}$ as Mayo score 0 . In the literature, the debate continues whether Mayo score 0 or 1 qualifies as a definition for $\mathrm{MH}[45,51]$. Still, in UC $40 \%$ of the participants indicated the definition of $\mathrm{MH}$ as 'macroscopic normal mucosa', and the same applied for $66 \%$ in CD. The latter is in accordance with the IOIBD consensus which agreed on the 'absence of ulceration' as an endoscopic target in CD [45]. Both CDEIS and SES-CD are validated scoring systems for $\mathrm{CD}$. Surprisingly, we found that only one-fifth use the CDEIS, and $9.6 \%$ the SES-CD, while the CDEIS is known as time consuming and complex [19,20,48].

The participants went through three clinical UC cases dealing with treatment targets and stopping criteria of immunosuppressive medication. In line with their answers on the theoretical questions concerning treatment targets in UC, most respondents chose to intensify the treatment to reach deep remission.

Our study has several strengths and some limitations. Mucosal healing has been a theme in clinical trial design but it was unknown whether this concept had been adopted in clinical practice. Our data suggest that it has. Secondly, this survey has been developed according to survey guidelines [29], and carried high internal consistency when comparing theoretical questions with practical cases. Naturally, the voluntary participation to this survey creates response bias. Since our target population was 'gastroenterologists who treat IBD patients', we chose a purposive sampling design and mentioned this element in the cover e-mail that was sent to possible participants.

The purposive sampling, national design of our survey, and the inclusion of physicians from both general and academic hospitals, were in support of the external generalizability of our findings. 


\section{CONCLUSION}

We demonstrated that the use of $\mathrm{MH}$, as a marker of treatment efficacy for both UC and CD, has made its way into routine practice. Although there is no single definition for $\mathrm{MH}$, the majority of gastroenterologists use endoscopic MAYO score $\leq 1$ in UC or 'macroscopic normal mucosa' in CD. This seems to be the least complex and most pragmatic definition for widespread use in clinical practice.

Conflicts of interest: None to declare.

Authors' contributions: T.E.H.R.: conception and design of the work, data collection, analysis and interpretation, drafting the article; K.G.: Data collection, analysis and interpretation; W.K.: data analysis and interpretation; F. H. and J.P.H.D.: critical revision of the article. All authors gave final approval of the version to be published.

Supplementary material: To access the supplementary material visit the online version of the J Gastrointestin Liver Dis at http://www.jgld. ro/wp/archive/ and http://dx.doi.org/10.15403/jgld.2014.1121.254.ken

\section{REFERENCES}

1. Bernstein CN, Loftus EV, Ng SC, Lakatos PL, et al. Hospitalisations and surgery in Crohn's disease. Gut 2012; 61: 622-629. doi: 10.1136/ gutjnl-2011-301397

2. Magro F, Rodrigues A, Vieira AI, et al. Review of the disease course among adult ulcerative colitis population-based longitudinal cohorts. Inflamm Bowel Dis 2012; 18: 573-583. doi: 10.1002/ibd.21815

3. Baars JE, Nuij VJ, Oldenburg B, Kuipers EJ, van der Woude CJ. Majority of patients with inflammatory bowel disease in clinical remission have mucosal inflammation. Inflamm Bowel Dis 2012; 18: 1634-1640. doi: 10.1002/ibd.21925

4. van Dullemen HM, van Deventer SJ, Hommes DW, et al. Treatment of Crohn's disease with anti-tumor necrosis factor chimeric monoclonal antibody (cA2). Gastroenterology 1995; 109: 129-135. doi: 10.1016/0016-5085(95)90277-5

5. Rutgeerts P, D'Haens G, Targan S, et al. Efficacy and safety of retreatment with anti-tumor necrosis factor antibody (infliximab) to maintain remission in Crohn's disease. Gastroenterology 1999; 117: 761-769. doi: 10.1016/S0016-5085(99)70332-X

6. Rutgeerts P, Diamond RH, Bala M, et al. Scheduled maintenance treatment with infliximab is superior to episodic treatment for the healing of mucosal ulceration associated with Crohn's disease. Gastrointest Endosc 2006; 63: 433-442. doi: 10.1016/j.gie.2005.08.011

7. Hanauer SB, Feagan BG, Lichtenstein GR, et al. Maintenance infliximab for Crohn's disease: the ACCENT I randomised trial. Lancet 2002; 359: 1541-1549. doi: 10.1016/S0140-6736(02)08512-4

8. Sands BE, Anderson FH, Bernstein CN, et al. Infliximab maintenance therapy for fistulizing Crohn's disease. N Engl J Med 2004; 350: 876-885. doi: 10.1056/NEJMoa030815

9. Walsh A, Palmer R, Travis S. Mucosal healing as a target of therapy for colonic inflammatory bowel disease and methods to score disease activity. Gastrointest Endosc Clin N Am 2014; 24: 367-378. doi: 10.1016/j.giec.2014.03.005

10. Theede K, Kiszka-Kanowitz M, Nordgaard-Lassen I, Mertz Nielsen A. The Impact of Endoscopic Inflammation and Mucosal Healing on
Health-related Quality of Life in Ulcerative Colitis Patients. J Crohns Colitis 2015; 9: 625-632. doi: 10.1093/ecco-jcc/jjv081

11. Barreiro-de Acosta M, Vallejo N, de la Iglesia D, et al. Evaluation of the Risk of Relapse in Ulcerative Colitis According to the Degree of Mucosal Healing (Mayo 0 vs 1): A Longitudinal Cohort Study. J Crohns Colitis 2016; 10: 13-19. doi: 10.1093/ecco-jcc/jjv158

12. Colombel JF, Rutgeerts P, Reinisch W, et al. Early mucosal healing with infliximab is associated with improved long-term clinical outcomes in ulcerative colitis. Gastroenterology 2011; 141: 1194-1201. doi: 10.1053/j. gastro.2011.06.054

13. Ardizzone S, Cassinotti A, Duca P, et al. Mucosal healing predicts late outcomes after the first course of corticosteroids for newly diagnosed ulcerative colitis. Clin Gastroenterol Hepatol 2011; 9: 483-489.e3. doi: 10.1016/j.cgh.2010.12.028

14. Baert F, Moortgat L, Van Assche G, et al. Mucosal healing predicts sustained clinical remission in patients with early-stage Crohn's disease. Gastroenterology 2010; 138: 463-468. doi: 10.1053/j. gastro.2009.09.056

15. Peyrin-Biroulet L, Ferrante M, Magro F, et al. Results from the 2nd Scientific Workshop of the ECCO. I: Impact of mucosal healing on the course of inflammatory bowel disease. J Crohns Colitis 2011; 5: 477-483. doi: 10.1016/j.crohns.2011.06.009

16. Travis SP, Schnell D, Krzeski P, et al. Reliability and initial validation of the ulcerative colitis endoscopic index of severity. Gastroenterology 2013; 145: 987-995. doi: 10.1053/j.gastro.2013.07.024

17. Travis SP, Schnell D, Krzeski P, et al. Developing an instrument to assess the endoscopic severity of ulcerative colitis: the Ulcerative Colitis Endoscopic Index of Severity (UCEIS). Gut 2012; 61: 535-542. doi: 10.1136/gutjnl-2011-300486

18. Mary JY, Modigliani R. Development and validation of an endoscopic index of the severity for Crohn's disease: a prospective multicentre study. Groupe d'Etudes Therapeutiques des Affections Inflammatoires du Tube Digestif (GETAID). Gut 1989; 30: 983-989. doi: 10.1136/gut.30.7.983

19. Daperno M, D’Haens G, Van Assche G, et al. Development and validation of a new, simplified endoscopic activity score for Crohn's disease: the SES-CD. Gastrointest Endosc 2004; 60: 505-512. doi: 10.1016/S0016-5107(04)01878-4

20. Khanna R, Bouguen G, Feagan BG, et al. A systematic review of measurement of endoscopic disease activity and mucosal healing in Crohn's disease: recommendations for clinical trial design. Inflamm Bowel Dis 2014; 20: 1850-1861. doi: 10.1097/MIB.0000000000000131

21. Pagnini C, Menasci F, Festa S, Rizzatti G, Delle Fave G. "Mucosal healing" in ulcerative colitis: Between clinical evidence and market suggestion. World J Gastrointest Pathophysiol 2014; 5: 54-62. doi: 10.4291/wjgp.v5.i2.54

22. Schroeder KW, Tremaine WJ, Ilstrup DM. Coated oral 5-aminosalicylic acid therapy for mildly to moderately active ulcerative colitis. A randomized study. N Engl J Med 1987; 317: 1625-1629. doi: 10.1056/ NEJM198712243172603

23. Travis SP, Higgins PD, Orchard T, et al. Review article: defining remission in ulcerative colitis. Aliment Pharmacol Ther 2011; 34: 113 124. doi: 10.1111/j.1365-2036.2011.04701.x

24. Ikeya K, Hanai H, Sugimoto K, et al. The Ulcerative Colitis Endoscopic Index of Severity More Accurately Reflects Clinical Outcomes and Long-term Prognosis than the Mayo Endoscopic Score. J Crohns Colitis 2016; 10: 286-295. doi: 10.1093/ecco-jcc/jjv210

25. Kornbluth A, Sachar DB; Practice Parameters Committee of the American College of Gastroenterology. Ulcerative colitis practice guidelines in adults: American College of Gastroenterology, Practice 
Parameters Committee. Am J Gastroenterol 2010; 105: 501-523. doi 10.1038/ajg.2009.727

26. Van Assche G, Dignass A, Panes J, et al. The second European evidencebased Consensus on the diagnosis and management of Crohn's disease Definitions and diagnosis. J Crohns Colitis 2010; 4: 7-27. doi: 10.1016/j. crohns.2009.09.009

27. Dignass A, Eliakim R, Magro F, et al. Second European evidence-based consensus on the diagnosis and management of ulcerative colitis part 1: definitions and diagnosis. J Crohns Colitis 2012; 6: 965-990. doi: 10.1016/j.crohns.2012.09.003

28. Initiative on Crohn's and Colitis and Dutch association of gastroenterologists. Instruction treatment IBD - 2014-2015; 1-119. Accessed march 23, 2016 at http://www.icc-ibd.com/richtlijn

29. Burns KE, Duffett M, Kho ME, et al. A guide for the design and conduct of self-administered surveys of clinicians. CMAJ 2008; 179: 245-252. doi: 10.1503/cmaj.080372

30. Schoepfer AM, Vavricka S, Zahnd-Straumann N, Straumann A, Beglinger C. Monitoring inflammatory bowel disease activity: clinical activity is judged to be more relevant than endoscopic severity or biomarkers. J Crohns Colitis 2012; 6: 412-418. doi: 10.1016/j.crohns.2011.09.008

31. Romkens TE, Kampschreur MT, Drenth JP, van Oijen MG, de Jong DJ. High mucosal healing rates in 5-ASA-treated ulcerative colitis patients: results of a meta-analysis of clinical trials. Inflamm Bowel Dis 2012; 18: 2190-2198. doi: 10.1002/ibd.22939

32. Lichtenstein GR, Ramsey D, Rubin DT. Randomised clinical trial: delayedrelease oral mesalazine $4.8 \mathrm{~g}$ /day vs. $2.4 \mathrm{~g} /$ day in endoscopic mucosal healing--ASCEND I and II combined analysis. Aliment Pharmacol Ther 2011; 33: 672-678. doi: 10.1111/j.1365-2036.2010.04575.x

33. Ardizzone S, Maconi G, Russo A, Imbesi V, Colombo E, Bianchi Porro G. Randomised controlled trial of azathioprine and 5-aminosalicylic acid for treatment of steroid dependent ulcerative colitis. Gut 2006; 55 : 47-53. doi: 10.1136/gut.2005.068809

34. Laharie D, Filippi J, Roblin X, et al. Impact of mucosal healing on longterm outcomes in ulcerative colitis treated with infliximab: a multicenter experience. Aliment Pharmacol Ther 2013; 37: 998-1004. doi: 10.1111/ apt.12289

35. Rutgeerts P, Sandborn WJ, Feagan BG, et al. Infliximab for induction and maintenance therapy for ulcerative colitis. N Engl J Med 2005; 353: 2462-2476. doi: 10.1056/NEJMoa050516

36. Sandborn WJ. Mucosal healing with infliximab: results from the active ulcerative colitis trials. Gastroenterol Hepatol 2012; 8: 117-119.

37. Mosli MH, MacDonald JK, Bickston SJ, et al. Vedolizumab for induction and maintenance of remission in ulcerative colitis: a Cochrane systematic review and meta-analysis. Inflamm Bowel Dis 2015; 21: 1151-1159. doi: 10.1097/MIB.0000000000000396

38. Mantzaris GJ, Christidou A, Sfakianakis M, et al. Azathioprine is superior to budesonide in achieving and maintaining mucosal healing and histologic remission in steroid-dependent Crohn's disease. Inflamm Bowel Dis 2009; 15: 375-382. doi: 10.1002/ibd.20777
39. Colombel JF, Sandborn WJ, Reinisch W, et al. Infliximab, azathioprine, or combination therapy for Crohn's disease. N Engl J Med 2010; 362: 1383-1395. doi: 10.1056/NEJMoa0904492

40. Colombel JF, Reinisch W, Mantzaris GJ, et al. Randomised clinical trial: deep remission in biologic and immunomodulator naive patients with Crohn's disease - a SONIC post hoc analysis. Aliment Pharmacol Ther 2015; 41: 734-746. doi: 10.1111/apt.13139

41. Rutgeerts P, Van Assche G, Sandborn WJ, et al. Adalimumab induces and maintains mucosal healing in patients with Crohn's disease: data from the EXTEND trial. Gastroenterology 2012; 142: 1102-1111.e2. doi: 10.1053/j.gastro.2012.01.035

42. Dulai PS, Singh S, Jiang X, et al. The Real-World Effectiveness and Safety of Vedolizumab for Moderate-Severe Crohn's Disease: Results From the US VICTORY Consortium. Am J Gastroenterol 2016; 111: 1147-1155. doi: 10.1038/ajg.2016.236

43. Peyrin-Biroulet L, Bressenot A, Kampman W. Histologic remission: the ultimate therapeutic goal in ulcerative colitis? Clin Gastroenterol Hepatol 2014; 12: 929-934.e2. doi: 10.1016/j.cgh.2013.07.022

44. Bryant RV, Burger DC, Delo J, et al. Beyond endoscopic mucosal healing in UC: histological remission better predicts corticosteroid use and hospitalisation over 6 years of follow-up. Gut 2016; 65: 408-414. doi: 10.1136/gutjnl-2015-309598

45. Peyrin-Biroulet L, Sandborn W, Sands BE, et al. Selecting Therapeutic Targets in Inflammatory Bowel Disease (STRIDE): Determining Therapeutic Goals for Treat-to-Target. Am J Gastroenterol 2015; 110: 1324-1338. doi: 10.1038/ajg.2015.233

46. D’Haens G, Sandborn WJ, Feagan BG, et al. A review of activity indices and efficacy end points for clinical trials of medical therapy in adults with ulcerative colitis. Gastroenterology 2007; 132: 763-786. doi: 10.1053/j.gastro.2006.12.038

47. Samaan MA, Mosli MH, Sandborn WJ, et al. A systematic review of the measurement of endoscopic healing in ulcerative colitis clinical trials: recommendations and implications for future research. Inflamm Bowel Dis 2014; 20: 1465-1471. doi: 10.1097/MIB.0000000000000046

48. Ket SN, Palmer R, Travis S. Endoscopic Disease Activity in Inflammatory Bowel Disease. Curr Gastroenterol Rep 2015; 17: 50. doi: 10.1007/ s11894-015-0470-0

49. Feagan BG, Reinisch W, Rutgeerts $\mathrm{P}$, et al. The effects of infliximab therapy on health-related quality of life in ulcerative colitis patients. Am J Gastroenterol 2007; 102: 794-802. doi: 10.1111/j.1572 0241.2007.01094.x

50. Sandborn WJ, Rutgeerts P, Feagan BG, et al. Colectomy rate comparison after treatment of ulcerative colitis with placebo or infliximab. Gastroenterology 2009; 137: 1250-1260. doi: 10.1053/j. gastro.2009.06.061

51. Yokoyama K, Kobayashi K, Mukae M, Sada M, Koizumi W. Clinical Study of the Relation between Mucosal Healing and Long-Term Outcomes in Ulcerative Colitis. Gastroenterol Res Pract 2013; 2013: 192794. doi: 10.1155/2013/192794 


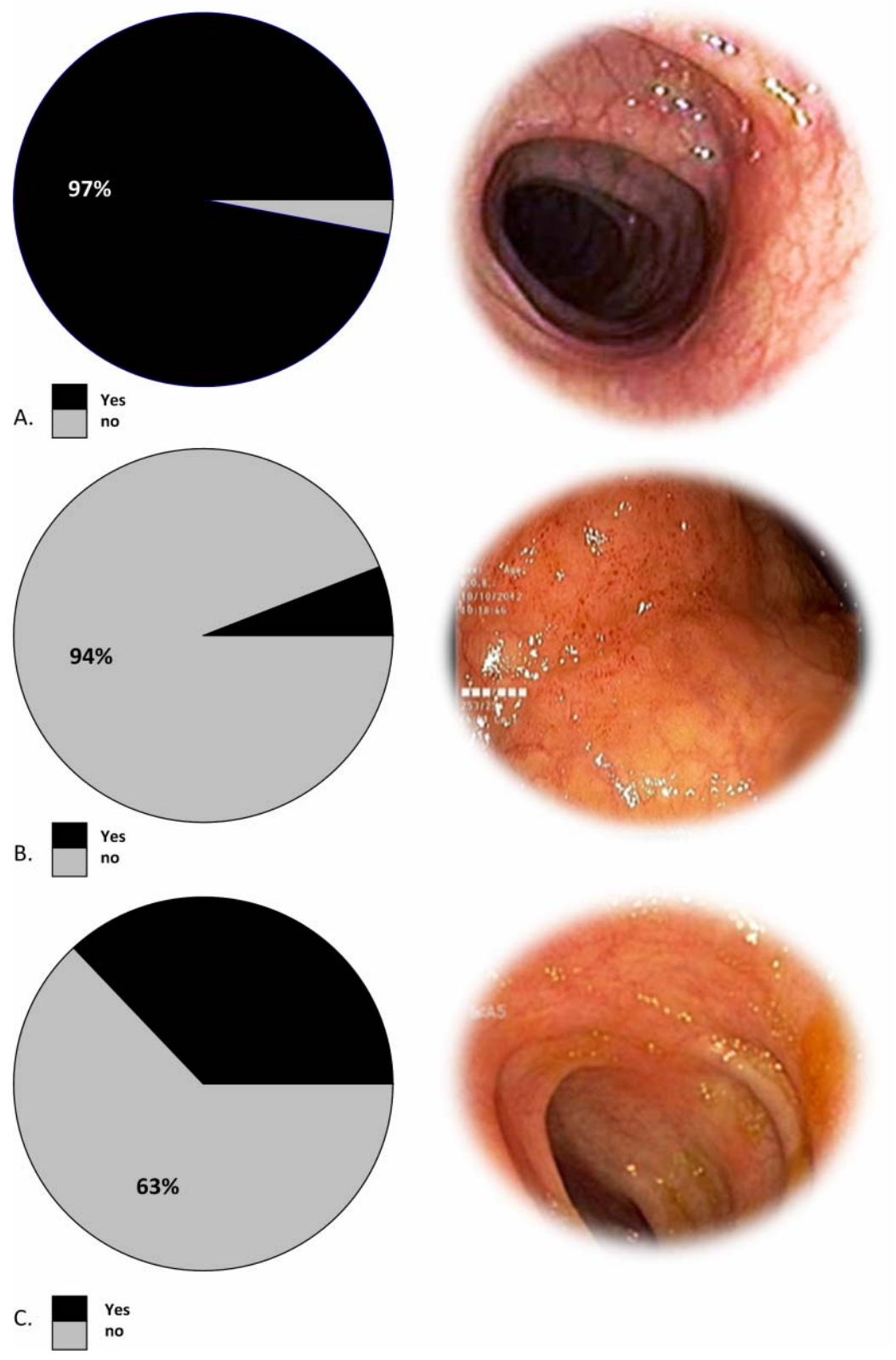

Fig. 3a-c. Endoscopy images and \% participants judging the image as mucosal healing 

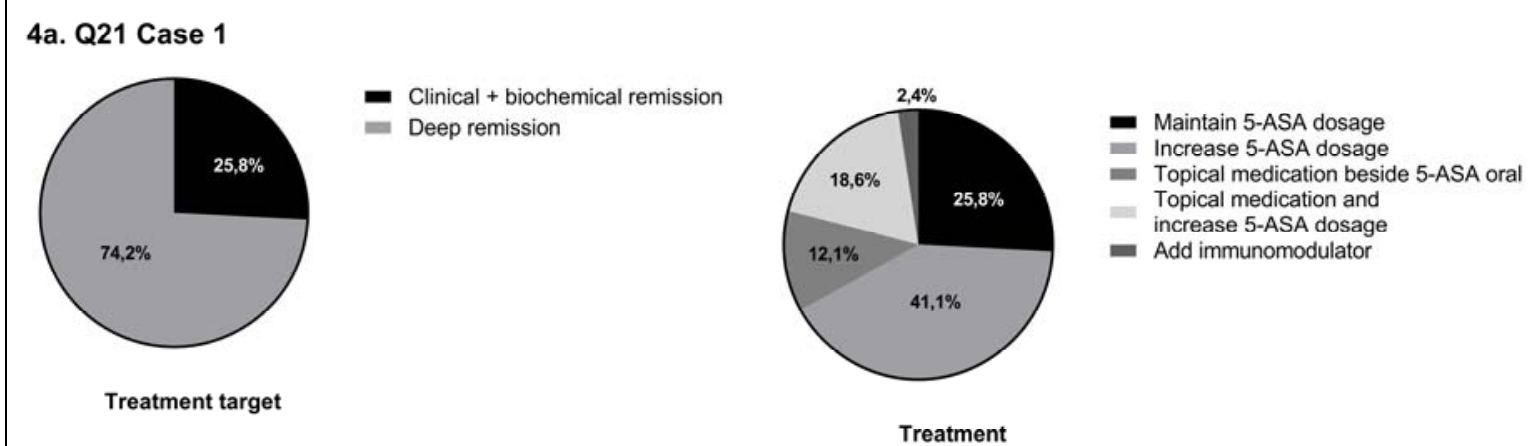

4b. Q22 Case 2
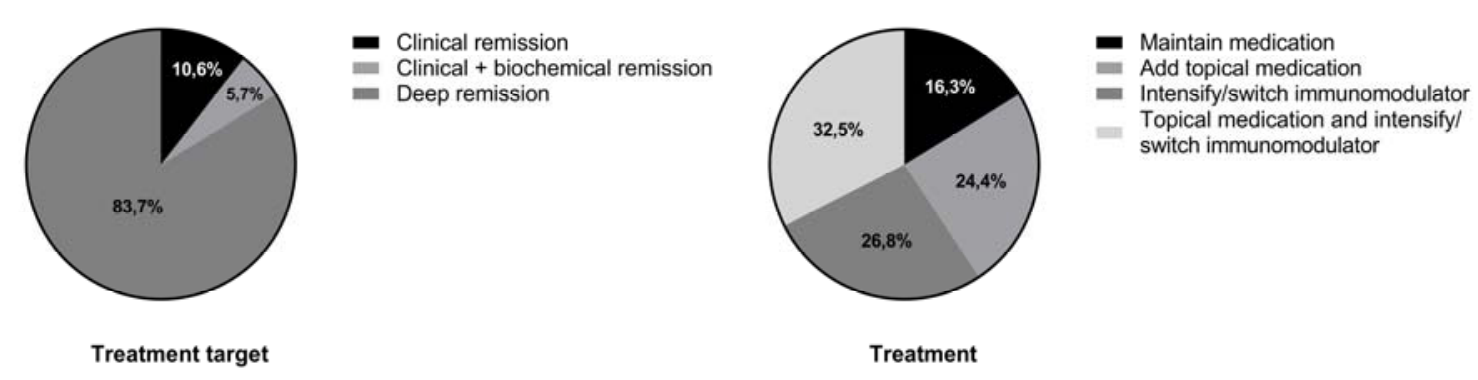

Fig. 4. Treatment targets and treatment options used to achieve treatment goals in case 1 (4a) and case $2(4 \mathrm{~b})$ 


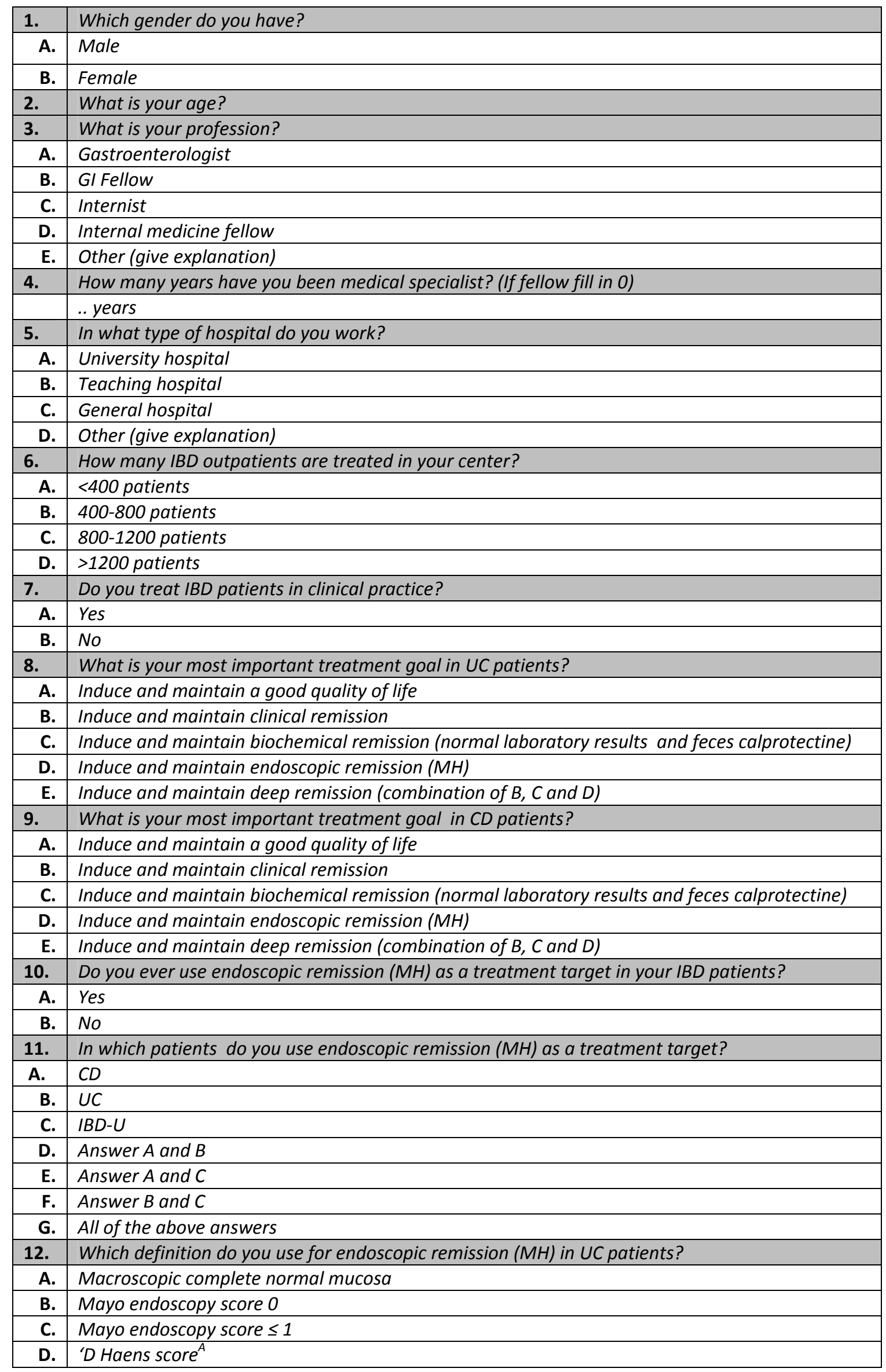




\begin{tabular}{|c|c|}
\hline E. & UCEIS score $0^{B}$ \\
\hline F. & $U^{\prime}$ CEIS ${ }^{B}$ score $<4$ \\
\hline G. & Other (give explanation) \\
\hline 13. & Which definition do you use for endoscopic remission $(\mathrm{MH})$ in $\mathrm{CD}$ patients? \\
\hline A. & Macroscopic complete normal mucosa \\
\hline B. & CDEIS score 0 \\
\hline C. & CDEIS ${ }^{C}$ score $<4$ \\
\hline D. & $S E S-C D^{D}$ \\
\hline E. & Other (give explanation) \\
\hline 14. & How do you define deep remission in your IBD patients? \\
\hline A. & Clinical remission \\
\hline B. & Clinical and biochemical remission \\
\hline C. & Clinical, biochemical and endoscopic remission \\
\hline D. & Clinical, biochemical endoscopic and histological remission \\
\hline 15. & $\begin{array}{l}\text { Do you ever use histological remission/microscopic mucosal healing (MMH) as a treatment } \\
\text { target in your IBD patients? }\end{array}$ \\
\hline A. & Yes \\
\hline B. & No \\
\hline 16. & In which patient group do you use $\mathrm{MMH}$ as a treatment target? \\
\hline A. & $C D$ \\
\hline B. & $U C$ \\
\hline C. & IBD-U \\
\hline D. & Answer $A$ and $B$ \\
\hline E. & Answer $A$ and $C$ \\
\hline F. & Answer $B$ and $C$ \\
\hline G. & All of the above answers \\
\hline 17. & Which definition for MMH do you use? \\
\hline A. & Truelove and Richards ${ }^{E}$ \\
\hline B. & Perfectly normal mucosa \\
\hline C. & Riley criteria $^{\digamma}$ \\
\hline D. & Geboes score ${ }^{G}$ \\
\hline E. & Other (give explanation) \\
\hline 18. & Do you think this image shows endoscopic remission? \\
\hline A. & Yes \\
\hline B. & No \\
\hline 19. & Do you think this image shows endoscopic remission? \\
\hline A. & Yes \\
\hline B. & No \\
\hline 20. & Do you think this image shows endoscopic remission? \\
\hline A. & Yes \\
\hline B. & No \\
\hline 21. & $\begin{array}{l}\text { (1/3) Case: } 45 \text { year old female; pancolitis ulcerosa since } 1994 \text {, is on } 2 \text { grams mesalazine/day } \\
\text { maintenance dose; no symptoms, normal laboratory results, feces calprotectine } 200 \mu \mathrm{g} / \mathrm{g} \text {. At } \\
\text { surveillance colonoscopy: sigmoiditis MAYO I. What is your treatment? }\end{array}$ \\
\hline A. & Maintain 5-ASA dose (patient is in clinical and biochemical remission) \\
\hline B. & Increase 5-ASA dose to achieve deep remission \\
\hline C. & Add topical medication to oral 5-ASA to achieve deep remission \\
\hline D. & Combination of B. and C. to achieve deep remission \\
\hline E. & Add an immunomodulator to achieve deep remission \\
\hline 22. & $\begin{array}{l}\text { (2/3) Case: } 22 \text { year old male, pancolitis ulcerosa since 2011; Severe disease course at } \\
\text { presentation: top down treatment with infliximab } 5 \mathrm{mg} / \mathrm{kg} \text { induction scheme followed by } \\
\text { maintenance therapy } 1 x / 8 \text { weeks combined with } 6-\mathrm{mercaptopurine.} \mathrm{Now:} \mathrm{no} \mathrm{symptoms,} \\
\text { laboratory results: CRP 10, feces calprotectine } 250 \mathrm{\mu g} / \mathrm{g} \text { and at colonoscopy rectosigmoiditis } \\
\text { MAYO II. What is your treatment? }\end{array}$ \\
\hline A. & Maintain current medication (patient is in clinical remission) \\
\hline B. & Maintain current medication (patient is in clinical and biochemical remission) \\
\hline C. & Add topical medication to current medication to achieve deep remission \\
\hline
\end{tabular}




\begin{tabular}{|c|l|}
\hline D. & Intensify/switch current immunomodulators (after control levels) to achieve deep remission \\
\hline E. & Combination of C. and D. \\
\hline 23. & $\begin{array}{l}\text { (3/3) Case: } 22 \text { year old male, pancolitis ulcerosa since 2011; Severe disease course at } \\
\text { presentation: top down treatment with infliximab } 5 \mathrm{mg} / \mathrm{kg} \text { induction scheme followed by } \\
\text { maintainance therapy } 1 x / 8 \text { weeks combined with 6-mercaptopurine. Since 1,5 years no } \\
\text { symptoms, laboratory results: normal, CRP }<5, \text { feces calprotectine 250 } \mathrm{\mu g} / \mathrm{g} \text { and normal mucosa } \\
\text { at colonoscopy What is your treatment? }\end{array}$ \\
\hline A. & Maintain current medication because of to "prognostic poor" ulcerative colitis \\
\hline B. & Stop anti-TNF therapy because of $>1$ year clinical, biochemical and endoscopic remission \\
\hline C. & Stop 6-mercaptopurine because of $>1$ year clinical, biochemical and endoscopic remission \\
\hline
\end{tabular}

${ }^{A_{1}}$ D Haens score = normaal ogende mucosa zonder: 1) toegenomen kwetsbaarheid, 2) bloedingen, 3) erosies, 4) zweren.

('D Haens score = normal-looking mucosa without:1) increased vulnerability, 2) haemorrhages, 3) erosions, 4)ulcers)

${ }^{\mathrm{B}}$ UCEIS = Ulcerative Colitis Endoscopy Index of Severity

${ }^{\mathrm{C}}$ CDEIS = Crohn's Disease Endoscopy Index of Severity

${ }^{\mathrm{D}} \mathrm{SES}-\mathrm{CD}=$ Simple Endoscopic Score for Crohn's Disease

${ }^{E}$ Truelove and Richards: graad 1: geen significante ontsteking, graad 2: mild-gemiddelde ontsteking, graad 3: ernstige ontsteking

(Truelove and Richards: grade 1: no significant inflammation, grade 2: mild-moderate inflammation, grade 3: severe inflammation)

F Riley: score van 6 kenmerken: acuut ontstekingsinfiltraat, crypt abcessen, mucus depletie, epitheliale integriteit, chronisch inflammatoir infiltraat, abnormaliteiten in crypte architectuur

( Riley: score of 6 features: acute inflammatory cell infiltrate, crypt abscesses, mucine depletion, surface epithelial integrity, chronic inflammatory cell infiltrate, crypt architectural irregularities)

${ }^{G}$ Geboes: score van 6 kenmerken: architecturele veranderingen, chronisch inflammatoir infiltraat, neutrofielen en eosinofielen in lamina propria, neutrofielen in epitheel, crypt destructie, erosie of ulceratie.

(Geboes: score of 6 features: architectural changes, chronic inflammatory infiltrate, lamina propria neutrophils and eosinophils, neutrophils in epithelium, crypt destruction, erosion or ulceration). 